\title{
DA PEDAGOGIA DO OPRIMIDO ÀS PEDAGOGIAS DA EXCLUSÃO: UM BREVE BALANÇO CRÍTICO*
}

\author{
DANILO ROMEU STRECK
}

\begin{abstract}
(...) o conhecimento está sempre se transformando. Isto é, o ato de saber tem historicidade, então o conhecimento de hoje sobre uma coisa não é necessariamente o mesmo de amanhã. O conhecimento transforma-se à medida que a realidade também se movimenta e se transforma. Então, a teoria também faz o mesmo. Não é algo estável, imobilizado. (Paulo Freire, em diálogo com Myles Horton, 2003, p. 114)
\end{abstract}

\begin{abstract}
RESUMO: $\mathrm{O}$ artigo tem por objetivo analisar alguns deslocamentos nas práticas pedagógicas que correspondem à mudança conceitual ao longo das quatro últimas décadas, mais precisamente desde a formulação da pedagogia do oprimido no fim da década de 1960 . Faz-se uma breve revisão do tema da exclusão social, em especial na sua vinculação com as políticas e práticas em educação, relacionando-o a três eixos explicativos identificados como consenso pedagógico, o deslizamento semântico de opressão para hegemonia e a crítica da modernidade e as teorias pós-modernas. Argumenta-se que o uso do binômio exclusão social/inclusão social encontra sua pertinência na denúncia das múltiplas desigualdades e no seu caráter instrumental para políticas públicas específicas. Paradoxalmente, nestes aspectos também se situam os seus limites em termos de projetar possibilidades de transformação da sociedade excludente.

Palavras-chave: Exclusão social. Paulo Freire. Práticas pedagógicas. Pedagogia da exclusão. Pedagogia do oprimido.
\end{abstract}

* O projeto do qual este trabalho é parte conta com o apoio do CNPq e com a colaboração dos seguintes bolsistas de Iniciação Científica: Daiane Azevedo (CNPq), Josiete Schneider (CNPq), Diulli Adriane Lopes Trindade (FAPERGS) e Vítor Schütz (UNISINOS).

** Doutor em Educação e professor do Programa de Pós-Graduação em Educação da Universidade do Vale do Rio dos Sinos (unisinos). E-mail: dstreck@unisinos.br

Educ. Soc., Campinas, vol. 30, n. 107, p. 539-560, maio/ago. 2009

Disponível em <http://www.cedes.unicamp.br> 
Da pedagogia do oprimido às pedagogias da exclusão: um breve balanço crítico

From PEDAGOGY OF THE OPPRESSED TO PEDAGOGIES OF EXCLUSION: A BRIEF CRITICAL BALANCE

ABSTRACT: This paper analyzes some shifts in pedagogical practices that correspond to the conceptual changes that have occurred in the last four decades, more precisely since the pedagogy of the oppressed was formulated, at the end of 1960s. It proposes a brief review of social exclusion, especially in terms of its implications for educational practices and policies, relating it to three explicative axes identified as: the pedagogical consensus; the semantic dislocation from oppression to hegemony, and; the critique of modernity and the post modern theories. It is argued that the social exclusion-social inclusion pair is relevant to denounce the multiple forms of inequalities and, as an instrument, to implement social policies. Paradoxically, these very aspects constitute its limits when it comes to projecting possibilities to transform the excluding social organization.

Key words: Social exclusion. Paulo Freire. Pedagogical practice. Pedagogy of exclusion. Pedagogy of the oppressed.

\section{Introdução}

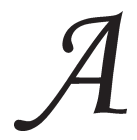

linguagem indica que se trata de outros tempos. Desde que Paulo Freire escreveu o hoje clássico Pedagogia do oprimido, ${ }^{1}$ na virada da década de $1960,{ }^{2}$ até os dias de hoje, quando surgem diferentes formatos de pedagogia da exclusão, houve importantes mudanças na sociedade que se refletem nas políticas educacionais e nas práticas educativas ou no sentido que se atribui a essas práticas. Ao mesmo tempo, pode-se argumentar que a realidade é a mesma. A saúde desatendida fere tanto ontem como hoje, os sintomas da fome são os mesmos no estômago de quem a sente e o desemprego significa hoje como então um obstáculo para a inserção digna na sociedade.

As discussões sobre modernidade e pós-modernidade, por um lado, e sobre a globalização e os movimentos que buscam uma globalização alternativa, por outro lado, têm trazido à tona os deslocamentos que ocorrem nos diferentes campos da atividade humana e que se dão na tensão entre rupturas e continuidades ou permanências. Uma visão linear da evolução dos fatos não será capaz de dar conta da leitura de nossos tempos e a discussão tende a se tornar infrutífera porque 
há argumentos razoáveis de ambos os lados. Além disso, o significado de conceitos como modernidade e globalização varia de acordo com o contexto em que são usados. É muito diferente falar de modernidade ou globalização a partir do centro onde os processos se constituíram do que falar deles desde a periferia, de um lugar que se viu inserido nesses processos de forma subalterna.

Neste ensaio haverá inicialmente uma tentativa de compreender o surgimento da pedagogia do oprimido e o seu contexto. Se a ideia da pedagogia do oprimido se espalhou como fogo num rastilho de pólvora em todos os continentes é porque havia um clima propício para a identificação com os argumentos expostos, quem sabe na mesma proporção que causava rejeição em outros. Uma característica de um clássico, lembra Ítalo Calvino (1993), é colocar em palavras o que todos aparentemente já sabiam e queriam ter dito. $\mathrm{O}$ autor empresta as suas palavras para o público, que delas se apropria muitas vezes como se fossem dele, ajudando a compor um novo senso comum. São códigos que passam a identificar grupos e práticas, dispensando maiores elaborações. Sabemos que isso tem o seu preço, uma vez que as ideias mais críticas não estão isentas de uma leitura acrítica. Também as ideias de Paulo Freire nunca estiveram livres desta leitura que ele chamava de mecanicista. Daí seu desabafo numa entrevista a Rosa Maria Torres no ano de 1985: "Não me compreendem. Não compreendem o que tenho dito, o que digo e o que tenho escrito" (Torres, 2007).

Uma questão que merece atenção especial é o embate entre os espaços formais e não-formais da educação. A pedagogia do oprimido teve o mérito, entre tantos outros, de refazer a geografia das práticas educativas, colocando a escola como um dos espaços possíveis da educação. Este deslocamento foi importante para que décadas depois se assumisse a pluralidade de contextos educativos, ao mesmo tempo em que se passou a repensar o papel clássico da escola como instituição formadora da modernidade. Se na sociedade medieval não havia possibilidade de salvação fora da Igreja, na modernidade essa possibilidade começa a ser concentrada na escola (Illich, 1972). O dentro e o fora da escola passaram a ser vistos como o dentro e o fora da própria sociedade. Com a pedagogia do oprimido há um novo olhar para as práticas pedagógicas presentes nos processos sociais e para os próprios processos sociais como mediações pedagógicas na construção de novos saberes e novas práticas. 
O segundo subtema da discussão trata dos acercamentos do sentido da exclusão social, em especial no campo da educação, procurando identificar alguns eixos que caracterizam esta expressão. Também no uso desse conceito é importante identificar o lugar de quem fala ou escreve. Estaríamos mais uma vez transplantando conceitos, por ingenuidade ou por astúcia? $\mathrm{O}$ conceito pode nos ajudar na compreensão de nossa realidade brasileira e latino-americana que é também, ao mesmo tempo, planetária? Supera o escopo deste trabalho fazer uma revisão sistemática dos muitos usos do conceito, ${ }^{3}$ colocando-se como prioridade deste ensaio compreender a dinâmica social na qual o conceito de exclusão social adquire o seu lugar na interpretação da realidade, especialmente no âmbito da educação.

Por fim, há uma tentativa de identificar algumas características das pedagogias da exclusão, relacionando-as com a pedagogia do oprimido. O que aparece de novo nas recentes articulações da teoria pedagógica? Haveria indícios dessas características na própria teoria freiriana? Se a exclusão social, conforme Aldaíza Sposati (1998), é sobretudo um conceito-denúncia, onde encontrar sinais de anúncio? A pedagogia do oprimido tinha na libertação o seu horizonte utópico e as práticas procuravam traduzir sinais desta libertação. Educação, dizia Paulo Freire em títulos de seus livros, como prática da liberdade ou como ação cultural para a liberdade. Onde estaria hoje este "inédito viável"?

\section{O oprimido e sua pedagogia}

Criou-se no imaginário coletivo da época atual a sensação de que é de hoje o privilégio ou o infortúnio de viver um tempo de incertezas, de riscos e de buscas. ${ }^{4}$ Se olharmos para a Pedagogia do oprimido, vemos que Freire lutava com questôes semelhantes há quase meio século e que talvez fosse mais adequado reconhecer que cada geração está confrontada com a tarefa intransferível de encontrar o seu "posto no cosmos". Segundo ele, o problema central que então assumia um "caráter ineludível” era o da humanização de homens e mulheres. Seria outro o problema central, hoje?

Freire está atento para o contexto em que os seres humanos realizam esta busca do "ser mais". Na nota de rodapé do primeiro capítulo ele fala das várias rebeliōes que estão ocorrendo, com atenção especial 
para a rebelião dos jovens (1968), que, segundo ele, “manifestam, em sua profundidade, esta preocupação em torno do homem e dos homens [sic!], como seres no mundo e com o mundo". Mas havia outras rebeliōes cujos reflexos foram tão ou mais expressivos que a rebelião dos jovens, como o movimento das mulheres, que alterou profundamente as relações de gênero, o movimento antirracista e o movimento anticolonialista, que culminou com a independência de países africanos e promoveu lutas por autodeterminação dos povos ao redor mundo.

As notas de rodapé indicam também os interlocutores que Paulo Freire escolhe para elaborar as suas idéias. Hegel e Marx aparecem junto com Erich Fromm, Karel Kosik, Althusser e Lúkacs; Franz Fanon e Albert Memmi com a fala de um camponês e o depoimento de um sociólogo; Marcuse, Sartre, Simone de Beauvoir, Martin Buber e Jaspers com Husserl; Reinhold Niebuhr com Gregório de Nissa e Mater et Magistra; Álvaro Vieira Pinto, José Luís Fiori e Francisco Weffort com Lucien Goldmann e Wright Mills; Che Guevara e Camilo Torres com Mao Tsé-Tung. As possibilidades de combinação dos nomes acima referidos, e de tantos outros não mencionados, são quase infinitas e dão uma ideia do caráter plural da obra de Freire.

Saliente-se, no entanto, que não se trata de uma simples justaposição de autores e ideias. Balduíno Andreola (2004) argumenta que o pensamento de Paulo Freire, mesmo que as partes aparentem desconexão entre si, volta-se a um projeto global de transformação e a uma nova sociedade. Estaríamos diante de uma original "pedagogia da simbiogênese e da solidariedade". Também Rosa Maria Torres (2007) no artigo intitulado Los multiples Paulo Freires escreve que pouco importa discutir se houve aqueles que entenderam Freire melhor que outros ou se há quem realmente o compreendeu. Segundo ela, "talvez a contribuição maior de Paulo Freire está em haver alcançado comunicar-se com as fibras mais amorosas e genuínas de muita gente".

Essa pluralidade se reflete na compreensão do oprimido. O oprimido é o ser humano alijado da condição de "ser mais" no sentido de realização da vocação de ser capaz de pronunciar o seu mundo como sujeito. É um ser histórico com uma subjetividade complexa cujos níveis de profundidade requerem, para a sua apreensão, uma "arqueologia da consciência”. Embora seja o portador da esperança de um futuro diferente, ele não está isento ou acima dos conflitos e das contradições 
Da pedagogia do oprimido às pedagogias da exclusão: um breve balanço crítico

da sociedade em que vive. A libertação será possível na medida em que houver uma assunção crítica dessas contradições, não apenas na teoria nem apenas na prática, mas na práxis que integra ação e reflexão como dois movimentos complementares em permanente tensão. Por isso Freire denuncia o "fatalismo libertador" inscrito em práticas e teorias que partem de leituras a-históricas da realidade.

O oprimido consubstancia-se como sujeito na luta pela liberdade. Paulo Freire situa-se entre aqueles que veem o sujeito histórico não como uma essência fixada em determinada classe ou grupo social, mas como emergência na história a partir de condiçôes de possibilidade que existem no oprimido. Este sujeito do ato de libertação é portador de virtudes como autonomia, dialogicidade, humildade, esperança e fé no ser humano. O sujeito forma-se à medida que o "ser para o outro" surge como um "ser para si”. Essa libertação implica, para Freire (1981, p. 70), também sempre o processo de transformação da estrutura que oprime.

Como marginalizados, "seres fora de" ou "à margem de", a solução estaria em que fossem "integrados", "incorporados" à sociedade sadia de onde um dia "partiram", renunciando, como trânsfugas, a uma vida feliz...

Sua solução estaria em deixarem de ser "seres fora de" e assumirem a de seres dentro de.

$\mathrm{Na}$ verdade, porém, os chamados marginalizados, que são os oprimidos, jamais estiveram fora de. Sempre estiveram dentro de. Dentro da estrutura que os transforma em "seres para outro". Sua solução, pois, não está em "integrar-se", em incorporar-se a essa estrutura que os oprime, mas em transformá-la para que possam fazer-se "seres para si".

A pedagogia do oprimido é o conjunto de práticas educacionais realizadas neste processo de transformação da estrutura que oprime. A revolução tem para Freire (1981, p. 59) "um caráter eminentemente pedagógico". Estão equivocados os líderes que para convencer as massas da necessidade das mudanças usam para isso os métodos que servem para a educação do opressor. $\mathrm{O}$ novo na pedagogia de Freire está exatamente em conceber a pedagogia a partir do outro e junto com o outro, que está à margem, e que desde este outro lugar tem a possibilidade de ousar pensar um mundo distinto daquele que existe. Como diz Ernani Maria Fiori (in Freire, 1981, p. 3) na apresentação da Pedagogia do oprimido: "Os caminhos da liberação são os do oprimido que 
se libera: ele não é coisa que se resgata, é sujeito que se deve autoconfigurar responsavelmente". É uma pedagogia que não está aí, pronta, apenas para ser descoberta. Ela terá de ser criada na práxis, entre educador e educando, na perspectiva do oprimido, por ele mesmo e por aqueles que veem na luta do oprimido a possibilidade de transformação da sociedade.

\section{As pedagogias da exclusão}

O livro Pedagogia do oprimido é dedicado "(a)os esfarrapados do mundo e aos que neles se descobrem e, assim, descobrindo-se, com eles sofrem, mas, sobretudo, com eles lutam" (1981, p. 17). Na Pedagogia da autonomia Freire reafirma o seu ponto de vista como sendo o dos "condenados da Terra, o dos excluídos" (1996, p. 16). Freire incorpora este novo conceito com uma naturalidade até surpreendente. De fato, pode-se argumentar que assumir esta nova nomenclatura faz parte do posicionamento epistemológico efetivado no livro Pedagogia da esperança (1992), quando a metáfora da trama assume uma importância central, sinalizando a necessidade de ser pós-modernamente progressista (Streck, 2001). Ou seja, a sociedade em movimento requer outra leitura, com novos conceitos. Paradoxalmente, a ideia de exclusão está fortemente associada com o neoliberalismo, contra o qual se volta a sua ira especialmente por não permitir espaço para a ação de homens e mulheres como sujeitos da história. ${ }^{5}$

Ao contrário do que acontece em Pedagogia do oprimido, não há neste seu último livro a preocupação com definiçōes. Pode-se especular que isso se deve, por um lado, ao fato de Freire valorizar uma continuidade básica em sua obra, a qual é dada, sobretudo, pelo posicionamento ético em favor dos "esfarrapados" (1970) ou dos condenados (1996) da Terra. Por outro lado, a nomenclatura parece ter um caráter secundário diante da realidade de seres humanos ameaçados em sua existência, independente do nome que se lhes atribui "de fora", a partir de esquemas teóricos. A introdução da expressão "ser gente" nos últimos escritos parece indicar um retorno ao que o ser humano tem de mais básico e que está ligado com a sua dignidade e liberdade.

Um ano antes da publicação de Pedagogia da autonomia (1996) havia sido lançada a coletânea Pedagogia da exclusão: crítica ao neoliberalismo 
Da pedagogia do oprimido às pedagogias da exclusão: um breve balanço crítico

em educação (Gentili, 1996). Fica patente que o uso do termo na pedagogia brasileira se dá no contexto do assim chamado "consenso de Washington", ${ }^{6}$ que sacramenta o uso das políticas neoliberais. Entre os temas do livro constam a privatização do ensino, o Banco Mundial e as políticas da educação, os mercados educacionais e o avanço da nova direita. Nas "Notas preliminares" o organizador, Pablo Gentili (1996, p. 9), chama atenção para o fato de que estes trabalhos "permitem caracterizar a ofensiva neoliberal como uma nova pedagogia da exclusão." Também Hugo Assmann (1996) usa o conceito exclusão para referirse à lógica excludente do mercado capitalista. Ele entende que exclusão tenha se tornado uma espécie de palavra-sintese para referir-se às novas características das desigualdades sociais no Brasil e no mundo. "Dívida social, apartheid social, e expressões similares, não expressam da mesma maneira o círculo vicioso da exclusão" (p. 214). Enumera então algumas características deste fenômeno da exclusão, entre as quais se destaca a existência de um enorme contingente de "inaproveitáveis" ou "desnecessários", a "massa sobrante". São perspectivas que estão em sintonia com o pensamento de Manuel Castells (1999, p. 98), que sintetiza sua ideia de exclusão social como significando um processo no qual determinados grupos e indivíduos estão impedidos do acesso a posiçóes que lhes garantam uma existência autônoma de acordo com os padróes de determinado contexto.

Vários autores argumentaram de maneira convincente que, como um fenômeno estrutural, a exclusão social é inerente ao processo de acumulação capitalista. Dentro dessa perspectiva, Avelino da Rosa Oliveira (2004a, p. 146) conclui seu estudo sobre Marx e a exclusão social afirmando que esta não pode constituir-se num conceito capaz de representar um novo paradigma social. ${ }^{7}$ Este argumento é retomado em Ghiggi e Oliveira (2007, p. 28): não estaríamos diante "de qualquer novidade substantiva que requeira um novo paradigma. (...) $\mathrm{O}$ modelo exclusão/inclusão é típico de uma perspectiva positivista-funcionalista, que apenas visa a corrigir as disfunçôes sociais, reatar os laços rompidos, supondo intocável a estrutura social".

José de Sousa Martins (2002) parte do mesmo pressuposto de que não se está diante de um novo dualismo, ressaltando em seus estudos que a sociedade que exclui é a mesma que inclui, no sentido de gerar formas desumanas de integração e participação no mesmo corpo 
social. Em sua frase irônica, "a novidade da chamada exclusão social é a sua velhice renovada” (p. 14). No entanto, segundo ele, a definição de exclusão social para identificar as desigualdades sociais hoje estaria também revelando um dos novos aspectos da sociedade de classes, ou seja, que a classe operária não mais ocupa o centro das explicações das lutas sociais.

É importante considerar que o conceito surge no norte, onde, na análise de Aldaíza Sposati (1998, p. 2), ele se refere a duas marcas desta sociedade: "A da perda de um patamar alcançado e do não-respeito à aquisição do novo direito à diferença. Ou a perda do lugar conquistado na responsabilidade pública, social e a discriminação quando da não-realização do direito à diferença”. O seu surgimento está geralmente vinculado à obra de René Lenoir (1974), para quem os excluídos são, de forma generalizada, os esquecidos do progresso ou os que por circunstâncias diversas não estão adaptados à sociedade, entre os quais os doentes mentais, os deficientes físicos e os anciãos.

Não é sem razão que Pedro Demo (1998) ironiza o "charme da exclusão social" à inglesa e à francesa. O conceito esconde uma espécie de saudade de um paraíso perdido, um sentimento que diz pouco para quem esta realidade nunca passou de miragem. Mas diz muito para quem se vê na iminência de "cair" para este outro mundo. Ulrich Beck (1998, p. 32) adverte para o risco da "brasilianização da Europa", com uma minoria rica e uma maioria pobre, resultante do "capitalismo desorganizado". Esta expressão traduz tanto o sentimento de iminente perda de privilégios acumulados ao longo de séculos de expansão capitalista quanto o eurocentrismo, a partir do qual o outro é visto como inferior e, nesta nova conjuntura, cada vez mais como ameaça. ${ }^{8}$

Como se percebe, tal como o fenômeno caracterizado como opressão nas décadas de 1960 e 1970, a exclusão social não se refere a algo novo nem uniforme (Knijnik, 1997). Parece que a generalização do uso da expressão exclusão social no campo da educação se deve a um conjunto de fatores, alguns deles atravessando os campos ideológicos, o que faz com que a expressão tenha um apelo de universalidade. As décadas de 1980 e 1990 correspondem a um movimento multifacetado da sociedade, com muitas contradições em todos os sentidos. Se, por um lado, houve o avanço das políticas neoliberais, é também o período da promulgação, na nova Constituição brasileira, da 
consolidação da institucionalidade democrática e da eleição de governos populares. A ideia de exclusão social faz parte deste contexto e refere distintas perspectivas dessa mesma realidade, entre as quais destacamos as seguintes: a) a exclusão social como referência ao consenso pedagógico; b) a exclusão social como campo de lutas múltiplas para a constituiçãa de uma nova hegemonia; c) a exclusão social como expressão do intento desconstrucionista das teorias pós-modernas.

\section{Um consenso pedagógico}

Assim como o consenso de Washington teve a intenção de prescrever as estratégias e os limites para ações possíveis na esfera da economia, na educação foi se formando um consenso sobre os limites da ação pedagógica. Isso está expresso em primeiro lugar nas reformas educacionais com ingredientes muito semelhantes em todos os continentes, dando a entender que efetivamente estamos num mundo globalizado e que, se o papel dos sistemas educacionais originalmente estava associado com a identidade dos povos tendo por base a soberania dos Estados nacionais, nestes novos tempos há uma realidade global a ser atendida. Criam-se para isso padrões internacionais que passam a balizar a avaliação desde o rendimento dos primeiros anos escolares até a produção científica dos pesquisadores. $\mathrm{Na}$ análise de Boaventura de Sousa Santos (2000, p. 330), este megassenso comum é resultado da "canibalização" da emancipação social pela regulação social, havendo se criado uma espécie de paralisia da subjetividade, tornada incapaz de conhecer e desejar para além da regulação.

Essas políticas uniformizadoras penetram o interior das práticas educativas, empurrando para segundo plano a teoria pedagógica, a qual muitas vezes se justifica apenas na medida em que serve para assegurar o cumprimento de metas de produtividade estabelecidas de fora (Magalhães \& Stoer, 2002). A exclusão social é vista como uma deformidade a ser vencida por meio da capacitação do indivíduo. Uma vez desenvolvidas as devidas competências, todos estariam aptos para serem incluídos na sociedade. Possivelmente nenhuma competência tenha recebido tanta atenção como o aprender a aprender. $\mathrm{Na}$ realidade a aprendizagem permanente faz parte da necessidade de adaptação do ser humano para a preservação da própria vida. No limite, a capacidade 
de aprender e a possibilidade de viver são sinônimos (Streck, 2001). Talvez hoje essa competência humana tenha se tornado efetivamente mais urgente e, neste sentido, o seu desenvolvimento deve receber uma atenção especial na educação. A falácia está na disseminação da ideia de que o fato de desenvolver essa capacidade seja suficiente para a integração plena na sociedade.

Também a crença da salvação pelas novas tecnologias faz parte desse novo consenso. Trocar as notas do quadro-negro por lâminas de power point que o aluno copia em seu caderno ou salva numa pasta eletrônica ainda não significa inovação pedagógica e muito menos o desenvolvimento de condições para a inserção crítica na sociedade. O uso do computador e de outros meios disponibilizados pela tecnologia é nada mais que um direito de quem vive nestes tempos. A inclusão digital é muitas vezes tratada como um fator capaz de garantir a superação da exclusão social, sem fazer referência à situação de desigualdade que está na origem da própria necessidade da inclusão. A competência tecnológica, analisa Bonetti (2000, p. 21), tornou-se o padrão referencial para igualar as diferenças, mais uma vez eximindo o Estado de sua responsabilidade pelas desigualdades. Este quadro faz parte do fenômeno que Boaventura de Sousa Santos (2006, p. 97) qualifica como "racionalidade metonímica", que reduz a experiência a uma mesma lógica e não permite a coexistência, em forma de ecologias, de distintos saberes, temporalidades, escalas, reconhecimentos e produtividades.

A noção de exclusão social serve, assim, ao propósito de reforçar o senso comum de que as alternativas de mudança não ultrapassam o nível do indivíduo ou, no máximo, do grupo mais imediato. São colocadas no mesmo patamar as políticas de inclusão de cegos ou surdos e políticas de inclusão de negros ou pobres. O que se perde com isso é a possibilidade de distinguir problemas que têm a ver com a estruturação classista da sociedade, em suas articulações com raça e gênero, ${ }^{9}$ de problemas que se situam num plano de habilidades e possibilidades do indivíduo ou de um grupo de indivíduos, no caso dos portadores de necessidades especiais. Não se trata também de hierarquizar os problemas, como se uns fossem menores que os outros, mas de distingui-los para que possam ser tratados de acordo com o contexto de práticas sociais e políticas em que se situam. O discurso da exclusão social tem o dom de mascarar essas diferenças. 
Da pedagogia do oprimido às pedagogias da exclusão: um breve balanço crítico

\section{A construção da hegemonia}

Giovanni Semeraro propõe que dois grandes conceitos podem sintetizar a filosofia política que orientou a educação popular na segunda metade do século passado. Nos anos de 1960 e 1970, que corresponde primeiro a um despertar das massas e depois ao movimento de reação e resistência às ditaduras militares, o grande tema foi o da libertação, representado, sobretudo, pelo pensamento de Paulo Freire. O conceito de hegemonia, tendo Gramsci como referência, teria sido o paradigma dos anos 80 e 90 . Independente de quem tenham sido as referências, até em virtude da proximidade do pensamento de Gramsci e Freire, ${ }^{10}$ sua análise mostra importantes deslocamentos ocorridos nesse período. Segundo ele, "o deslizamento de vocabulário" sinaliza essas mudanças de paradigma: de opressão para hegemonia, de libertação para direção, de identidade para projeto, dos movimentos para os partidos, do diálogo para o poder, da mística para a estratégia.

Nos anos de 1980, a disputa não era mais entre os movimentos populares e o Estado, mas entre projetos da sociedade civil burguesa e projetos emanados do movimento popular. Houve, neste sentido, importantes conquistas: a Constituição de 1988 incorporou aspectos reivindicados pelos movimentos sociais em muitas áreas; também o orçamento participativo de Porto Alegre nasceu como resultado da luta dos movimentos sociais por uma participação efetiva na gestão pública por meio de um governo popular. Em contrapartida, nas palavras de Semeraro (2006, p. 32), "a concentração das atençōes nos partidos, a profissionalização da política e o dispêndio de energia acabaram esvaziando os espaços voltados para a educação popular e esvaziando muitos movimentos sociais".

Dentro dessa compreensão, a exclusão social e o seu correlato - a inclusão social - deixam de ser vistas como uma questão meramente individual, mas assumem um caráter coletivo como possibilidade de ocupar espaços na luta pela construção de uma nova hegemonia. Por exemplo, a política de cotas é vista como uma política inclusiva e pode ter várias leituras dentro do mesmo campo ideológico favorável à superação da desigualdade racial. Para uns, é mais uma vez uma concessão do Estado que contribui para esvaziar os movimentos que lutam por uma transformação das estruturas da sociedade. Para outros, é um passo nessa mesma luta que continuará sendo desdobrada em várias frentes. 


\section{A critica da modernidade e as teorias pós-modernas}

As teorias pós-modernas tiveram o inegável mérito de colocar sob suspeita as verdades da ciência e a própria ciência moderna. No campo social esse pensamento está presente em discursos de teor semelhante sobre o fim das utopias, o fim da história, o fim da sociedade, o fim do sujeito, entre outros. O que esses discursos têm em comum é a assunção de limites para o agir humano, confundido muitas vezes com acomodação ao status quo.

No pensamento de Paulo Freire essa mudança é sinalizada pela importância dada por ele à metáfora da trama. Na Pedagogia da esperança (1992), em meio aos embates ideológicos que anteriormente apontamos e num período em que muito se lamentava o refluxo do movimento popular, Paulo Freire escreve uma pedagogia que se coloca decididamente contra a desesperança derivada do sentimento de impotência diante dos acontecimentos.

É também nesse contexto que ele formula a sua versão sobre a relação entre a modernidade e a pós-modernidade. Para ele, os ideais que moveram a modernidade não podem ser descartados, ainda mais por quem nunca chegou a usufruir os seus benefícios. Ao mesmo tempo, a época exige outro tipo de postura e de leitura, que ele caracteriza como pós-moderna. Precisa-se ser, segundo Freire (1992, p. 81), "pósmodernamente progressista”. Algo semelhante ao que o filósofo Enrique Dussel (1993) expressa com o seu conceito de transmodernidade, ${ }^{11}$ que não vê a modernidade como uma fase a ser seguida por outra, mas como um movimento que dialeticamente a supera, dela incorporando os elementos emancipadores, mas subsumidos numa ética da vida que respeita a alteridade.

A noção de exclusão social, portanto, tem o seu lugar neste contexto da trama que incorpora a complexidade inerente à leitura dos novos tempos, quando vozes diferentes se fazem ouvir no cenário cultural, social e político com suas narrativas próprias. São vozes que cada vez mais querem contar a sua estória, com suas palavras, e construir os seus significados. ${ }^{12}$ Trata-se, na expressão de Stoer, Magalhães e Rodrigues (2004, p. 108), de uma verdadeira "rebelião das diferenças", quando estas se posicionam contra ditames epistemológicos, sociológicos e políticos que procuram incluí-las em narrativas prontas. 
Da pedagogia do oprimido às pedagogias da exclusão: um breve balanço crítico

\section{O alcance da noção de exclusão social no campo da educação}

O pressuposto nesta discussão é de que conceitos são instrumentos para a leitura de nosso mundo. Se, por um lado, sua criação e uso têm um inescapável grau de arbitrariedade, também é necessária uma legitimação social e pública para a sua eficácia na comunicação. $\mathrm{O}$ uso do binômio exclusão social/inclusão social encontra sua pertinência no contexto da denúncia e do pragmatismo, onde paradoxalmente também se revelam os seus limites.

O seu potencial como fator de denúncia fica evidente na grande marcha que a cada ano é realizada sob os auspícios de setores progressistas da Igreja Católica com o nome de Grito dos Excluídos e também na mistura de pessoas e de grupos que compõem o Fórum Social Mundial (Streck, 2004). Há uma correspondência entre exclusão social e os assim chamados novos movimentos sociais, que têm no reconhecimento identitário uma importante bandeira de luta. ${ }^{13}$ Podem ser as mulheres, os jovens, os negros, os índios, os sem-terra ou os semteto, cada um deles por sua vez eventualmente subdividido em novos grupos. $\mathrm{Na}$ ecologia, pode haver grupos que lutam pela sobrevivência de uma espécie vegetal ou animal, grupos que lutam pela preservação da Amazônia, contra a ocupação predatória do solo etc. Todos eles encontram sob o manto da exclusão social algum tipo de abrigo.

Talvez se pudesse dizer que o deslizamento linguístico da opressão/libertação para exclusão/inclusão social implica um deslocamento do político para o ético. Libertação era um conceito de mobilização política da classe oprimida em busca da construção de outra sociedade. Na medida em que os contornos do horizonte dessa libertação se tornaram mais difusos, o conceito perde muito de sua força. Isso se deve tanto a fatores internos, com a assunção do poder por forças progressistas que frustram expectativas, como a fatores externos simbolizados na queda do muro de Berlim e à consequente sensação da impossibilidade de construção de alternativas que tenham condiçôes de se sustentar no cenário global.

Grosso modo, a exclusão social pode ser definida como a limitação de acesso às condições de vida consideradas dignas dentro de critérios éticos com reclamos de universalidade. São cada vez mais as próprias diferenças que dizem o que é digno a partir de suas particularidades. ${ }^{14}$ Isso pode levar, como já foi alertado por Pierucci (1999), a 
um relativismo que em última instância reforça desigualdades existentes ou cria novas. ${ }^{15}$ Por isso a necessidade de princípios que digam respeito a toda a sociedade e a todas elas.

Em Freire o reconhecimento da diferença como riqueza da humanidade é combinado com o que ele chama de ética universal do ser humano. A identificação do que seja a dignidade tem a ver com o contexto específico, mas também com uma compreensão de pertencimento a uma mesma espécie planetária. As condições de diferenciação entre os ricos pelo rótulo do vinho e outras sofisticaçóes têm a ver com a indignidade da fome em países do Terceiro Mundo. A partir daí também se dá o inescapável encontro do ético com o político. É, no entanto, uma sinalização de que a conquista de espaços e de poder, em si, não é condição suficiente para a transformação da sociedade.

O binômio exclusão social/inclusão social tem também um inegável valor pragmático. Já apontamos seu uso no debate de políticas públicas em várias áreas das práticas sociais. Se isso traz ambiguidades, também possibilita acordos entre os campos políticos para promover "inclusões" que, embora subalternas do ponto de vista da estrutura social existente, representam avanços para quem delas se beneficia. ${ }^{16}$

O uso pragmático também se verifica no mundo acadêmico e ali cumpre um papel semelhante ao que desempenha no campo das políticas. Este pragmatismo se manifesta de duas formas: pela possibilidade de descrever indicadores e aproximar a reflexão teórica da busca de dados empíricos e pelo desdobramento em diferentes "nomes" a partir de distintas leituras da realidade.

No primeiro aspecto, destaca-se o amplo trabalho que Márcio Pochmann (2004) e sua equipe de pesquisa vêm divulgando periodicamente no Atlas da exclusão social. Para a investigação que possibilita este mapeamento são indispensáveis indicadores que permitam organizar dados estatísticos já existentes ou levantar outros pertinentes. A exclusão social pode ser medida a partir dos seguintes índices desenvolvidos pela equipe: a) para a dimensão vida digna: pobreza dos chefes de família, taxa de emprego formal sobre a População Economicamente Ativa (PEA), desigualdade de renda; b) para a dimensão conhecimento: taxa de alfabetização, número médio de anos de estudo do chefe de família; c) para a dimensão vulnerabilidade: porcentagem de jovens 
Da pedagogia do oprimido às pedagogias da exclusão: um breve balanço crítico

na população e violência. Estes indicadores são passíveis de discussão e outros pesquisadores podem desenvolver outros atlas com base em outras definições. Não deixa de ser relevante, no entanto, que o conceito facilita ou até exige esta proximidade com a concretude das condições de vida.

Fernando Gil (2002), por sua vez, distingue entre um enfoque simples e um enfoque complexo da exclusão social. No primeiro caso, trata-se de uma visão maniqueísta segundo a qual todos sabemos quem são os excluídos e o que cabe fazer, desde a solidariedade por parte dos cidadãos à vontade política. Numa visão complexa reconhece-se a multiformidade da exclusão social considerando seus graus e níveis, os processos causadores de exclusão, a relação entre os diversos tipos de exclusão, a relação entre os efeitos excludentes e includentes dos fenômenos sociais, e a consciência e o conhecimento do caráter paradoxal destes fenômenos.

Quanto ao segundo aspecto apontado, basta ver os muitos significados atribuídos à exclusão social, numa indicação de que o estado a que este conceito se refere é passível de leituras diferentes e mesmo divergentes. Ao longo da história esse mesmo estado teve o sentido de ostracismo entre os atenienses, de proscrição em Roma, do pária na civilização hindu ou do gueto da Idade Média (Xiberras, 1993). Nas teorias sociológicas clássicas podia significar a dominação de classe (Marx), a ruptura da coesão social (Durkheim, Simmel, Weber) ou o desvio da norma (Escola de Chigago). ${ }^{17}$

As análises atuais traduzem a exclusão social como desfiliação, descarte, invisibilização, desqualificação, o mundo dos sobrantes, quarto mundo, desintegração, entre outros tantos sentidos. Este fato não pode ser atribuído simplesmente à falta de rigorosidade conceitual dos cientistas sociais, que fazem suas opções entre os termos existentes ou criam outros a partir de novas combinações. Parece que a elasticidade do conceito exclusão social favorece o encontro de perspectivas e as coloca diante do desafio de explicitação, questionando a rotulação fácil a partir de uma ou outra teoria.

Os mesmos motivos anteriormente apontados, que justificam o uso do conceito de exclusão social, também já indicam os seus limites. A amplitude e a pragmaticidade estão ligadas basicamente ao fato de lidarem com os sintomas da realidade social sem os referir às estruturas da sociedade, responsáveis por sua produção e reprodução. Este 
ocultamento dificulta posicionar as ações dentro de um quadro de referência que indique um horizonte de transformação social para além das inclusões de caráter geralmente compensatório e subordinado.

Talvez o jeito de Paulo Freire lidar com o problema conceitual em sua historicidade possa servir de exemplo ou inspiração. Houve, em sua obra, importantes deslocamentos conceituais vinculados com as mudanças da sociedade e as respectivas leituras. Em Educação como prática da liberdade a ideia de trânsito - do homem-objeto ao homem-sujeito, da sociedade fechada à sociedade aberta, da consciência ingênua à consciência crítica - expressa a expectativa de uma mudança em vias de realização por meio dos projetos que, naquela época de grande mobilização popular, estavam sendo desenvolvidos. $\mathrm{Na} \mathrm{Pe}$ dagogia do oprimido torna-se central a noção de conflito entre oprimidos e opressores, numa ruptura com a linearidade sugerida pelo conceito de trânsito. Em Pedagogia da esperança, a metáfora da trama indica novos tempos, novas leituras e novas pedagogias. A continuidade não está dada pelo apego a uma ou outra teoria, mas deve-se à escuta das práticas educativas que, em seu tempo, desafiam a busca de novos referenciais. Continua o desafio do trânsito da consciência, do ser humano e da sociedade em direção ao "ser mais". A luta pela libertação dos oprimidos não perdeu a sua vigência. Mas ambos os processos são ressignificados em outro contexto sociopolítico.

O argumento de Boaventura de Sousa Santos (1996) de que estamos num período de mudanças paradimáticas encontra eco na busca por uma linguagem que traduza a realidade. Os usos do binômio exclusão social/inclusão social na área da educação parecem ser uma expressão de incertezas epistemológicas que, conforme este autor, acompanham estes períodos de transição. Se, por um lado, a multiplicidade de vozes torna difícil reconhecer caminhos e direções, por outro, ela também desafia à criatividade e ao diálogo.

Recebido em novembro de 2007 e aprovado em abril de 2008.

\section{Notas}

1. A expressão pedagogia do oprimido será usada em duas acepções. Uma, no sentido lato, quando a grafia não terá nenhuma identificação especial, e no sentido estrito do título de uma obra de Paulo Freire. 
2. A primeira edição em português e em inglês data de 1970. Sabe-se, no entanto, que já antes o livro circulava, naqueles tempos de ditadura militar em grande parte dos países latino-americanos, de forma clandestina. Conforme seu depoimento (Freire, 1992, p. 53), ele escreveu o livro entre 1967 e 1968. Antes disso, no entanto, levou um ano ou mais "falando" o livro.

3. Importantes contribuições para uma visão sistematizada do tema da exclusão podem ser encontradas em Xiberras (1993), Demo (1998) e Oliveira (2004b).

4. Segundo Castel (2004, p. 77), "a atual inflação da sensibilidade dos riscos faz da busca da seguridade uma busca infinita e sempre frustrada". Haveria de se distinguir riscos que decorrem de contingências da vida, que são socializáveis e contra os quais é possível proteger-se, daqueles riscos que devem ser assumidos como limites, ainda que provisórios.

5. O dossiê Globalização e educação apresenta uma coletânea de excertos de artigos e livros nos quais Paulo Freire se refere ao neoliberalismo e à globalização sob o título "Referenciais freirianos: globalização e neoliberalismo na obra de Paulo Freire" (Carmo et al., 2006, p. 22-46).

6. O conceito consenso de Washington é atribuído ao economista inglês John Williamson, do Institute for International Economics, de Washington, DC, que o utilizou num artigo, em 1989, para resumir alguns pontos que pareciam consensuais para promover o desenvolvimento da América Latina. Dentre estes se destacam a disciplina da política fiscal, o redirecionamento dos gastos públicos para serviços básicos, como educação básica, saúde básica e investimentos em infraestrutura, a ampliação da base de taxação e a adoção de taxas moderadas, taxas de intercâmbio comercial competitivas, liberalização do comércio, privatização de propriedade estatal, liberalização do comércio de restrições para importação e segurança legal para direitos de propriedade.

7. Sobre a constituição da exclusão social como um novo paradigma a partir do qual a sociedade atual toma consciência de si e de suas disfunções, veja Paugam (1996).

8. "A dialética da representação do colonizado faz deste (...) um ser simultaneamente atractivo e repulsivo, um ser dócil e ameaçador, leal e traiçoeiro, um ser utópico e diabólico. Daí que os estereótipos não sejam unívocos nem consistentes. Consoante as necessidades de representação do colonizador, predominam estereótipos negativos ou, pelo contrário, estereótipos positivos, ainda que uns e outros se pertençam mutuamente" (Santos, 2006, p. 255).

9. Para uma análise das relaçôes entre as desigualdades de classe, gênero e etnia, veja Enguita (1996).

10. Conforme a citação em epígrafe, parece pertinente afirmar que Freire se reinventa, o que significa dizer que em contextos históricos e sociais distintos haverá outras fontes inspiradoras para Freire, incluindo Gramsci (Streck, 2001).

11. "Trata-se de uma 'Transmodernidade' como projeto mundial de libertação em que a Alteridade, que era coessencial da Modernidade, se realize igualmente. A 'realização' da Modernidade não se faz numa passagem da potência da modernidade para a atualidade da referida modernidade européia. A 'realização' seria agora a passagem transcendente, em que a Modernidade e sua Alteridade negada (as vítimas) se realizarão por mútua fecundidade criadora" (Dussel, 1993, p. 187).

12. Essa busca de sua voz também se refere cada vez mais aos pobres, conforme as palavras de Cyntia Sarti (1996, p. 20), quando critica a redução da pobreza a um paradigma produtivista: "Os pobres foram pensados, nessa perspectiva 'produtivista', a partir de 
uma visão na qual, no entanto, eles próprios não se reconhecem, o que foi considerado marca de sua 'alienação' ou 'falsa consciência'. Em outras palavras, os pobres foram pensados como se sua identidade social fosse ou devesse ser construída exclusivamente a partir de sua determinação de classe (...). A determinação de classe dos pobres que vivem na cidade, embora defina sua posição estrutural na sociedade onde se inserem como pobres, não constitui a única referência a partir da qual operam e constroem sua explicação do mundo e do lugar que nele ocupam".

13. "Mais do que nunca, não nos é possível construir escalas de estratificação confiáveis a partir da ideia de classes antagônicas. As relações de dominação nem por isso desapareceram, pelo contrário; mas já não permitem que as desigualdades reais sejam descritas objetivamente. A dominação já não se insere nas relações de classes concretas e estáveis. Os problemas da estratificação e da mobilidade se destacam dos conflitos estruturais e a análise das desigualdades não conduz a uma visão organizada e estruturada das relaçóes sociais" (Dubet, 2001, p. 10).

14. "Dizíamos que o respeito à diferença era uma ideia muito cara à educação popular. Hoje percebemos com mais clareza que a diferença não deve apenas ser respeitada. Ela é a riqueza da humanidade, base de uma filosofia do diálogo" (Freire, em Gadotti et al., 2000, p. 7).

15. "Ora muito bem, estas novas divisas de esquerda que giram em torno do 'direito à diferença' trazem consigo um ardil, instalado justamente nesta sua ambiguidade, uma debilidade hereditária: o fato de ter sido o amor à diferença alimentado no campo (ultra)conservador duzentos anos a fio, e só mui recentemente ter sido incorporado nalgumas faixas ou zonas do campo de esquerda. Este fato torna o atual clamor pelo 'direito à diferença' dificilmente distinguível da defesa das diferenças própria do estoque de certezas do senso comum conservador e do pensamento de direita" (Pierucci, 1999, p. 31).

16. Veja-se a conclusão do estudo de Maria Ozanira da Silva e Silva (2007) sobre as políticas sociais de transferência de renda atualmente em curso no Brasil: "Considerando a problematização e os resultados das pesquisas referenciadas, reafirmo que os Programas de Transferência de Renda, quando não articulados a uma política macroeconômica de crescimento sustentável e de redistribuição de renda, podem significar melhorias imediatas das condiçôes de vida, de famílias que vivem em extrema pobreza, o que já é importante, mas não superam a pobreza, ultrapassando, somente em caráter marginal, a denominada linha de pobreza”.

17. Para uma análise das teorias clássicas e das teorias do desvio, veja Xiberras (1993).

\section{Referências}
ANDREOLA, B. Paulo Freire do ponto de vista da interdisciplinari- dade. In: Streck, D.R. (Org.). Paulo Freire: ética, utopia e educação. 6. ed. Petrópolis: Vozes, 2004.
ASSMANN, H. Metáforas novas para reencantar a educação: epistemo- logia e didática. Piracicaba: UNIMEP, 1996.

BECK, U. Was ist Globalisierung?. Frankfurt am Main: Suhrkamp, 1998. 
Da pedagogia do oprimido às pedagogias da exclusão: um breve balanço crítico

BONETTI, L.W. (Org). Políticas públicas, educação e exclusão social. In: BonetTi, L.W. Educação, exclusão e cidadania. Ijuí: Unijuí, 2000.

CALVINO, I. Por que ler os clássicos. São Paulo: Cia das Letras, 1993.

CARMO, A.M. et al. Referenciais freirianos: globalização e neoliberalismo na obra de Paulo Freire. Educação \& linguagem, São Bernardo do Campo, v. 9, n. 13, p. 22-46, jan./jun. 2006.

CASTEL, R. La inseguridad social: qué es estar protegido? Buenos Aires: Manantial, 2004.

CASTELLS, M. Fim de milênio. São Paulo: Paz \& Terra, 1999.

DEMO, P. Charme da exclusão social. Campinas: Autores Associados, 1998. (Polêmicas do nosso tempo, 61)

DUBET, F. As desigualdades multiplicadas. Revista Brasileira de Educação, Belo Horizonte, n. 17, p. 5-19, maio/ago. 2001.

DUSSEL, E.D. 1492 o encobrimento do outro: a origem do "mito da modernidade". Petrópolis: Vozes, 1993.

ENGUITA. M.F. Os desiguais resultados das políticas igualitárias: classe, gênero e etnia na educação. Revista Brasileira de Educação, Belo Horizonte, n. 3, p. 5-17, set./dez. 1996.

FREIRE, P. Pedagogia do oprimido. 9. ed. Rio de Janeiro: Paz \& Terra, 1981.

FREIRE, P. Pedagogia da esperança: um reencontro com a pedagogia do oprimido. Rio de Janeiro: Paz \& Terra, 1992.

FREIRE, P. Pedagogia da autonomia: saberes necessários à prática educativa. Rio de Janeiro: Paz \& Terra, 1996.

FREIRE, P. Pedagogia da indignação: cartas pedagógicas e outros escritos. São Paulo: UNESP, 2000.

FREIRE, P.; HORTON, M. O caminho se faz caminhando: conversas sobre educação e mudança social. Petrópolis: Vozes, 2003.

GADOTTI, M. Educar para um outro mundo possivel. São Paulo: Publisher Brasil, 2007. 207 p. 
GADOTTI, M.; FREIRE, P.; GUIMARÃES, S. Pedagogia: diálogo e conflito. 5. ed. São Paulo: Cortez, 2000.

GENTILI, P. (Org.). Pedagogia da exclusão: crítica ao neoliberalismo em educação. 2. ed. Petrópolis: Vozes, 1996.

GHIGGI, G.; OLIVEIRA, A.R. Formação humana e exclusão social: repensando possibilidades, revigorando limites. Educação UNISINOS, São Leopoldo, v. 11, n. 1, p. 22-29, jan./abr. 2007.

GIL, F. La exclusión social. Barcelona: Ariel, 2002.

ILLICH, I. Deschooling society. New York: Harrow, 1972.

KNIJNIK, G. As novas modalidades de exclusão social: trabalho, conhecimento e educação. Revista Brasileira de Educação, Belo Horizonte, n. 4, p. 35-42, jan./abr. 1997.

LENOIR. Les exclus: un français sur dix. Paris: Seuil, 1974.

MAGALHÃES, A.M.; STOER, S. A escola para todos e a excelência acadêmica. Porto: Profedições, 2002.

MARTINS, J.S. A sociedade vista do abismo: novos estudos sobre exclusão, pobreza e classes sociais. 2. ed. Petrópolis: Vozes, 2003.

OLIVEIRA, A.R. Marx e a exclusão. Pelotas: Seiva, $2004 a$.

OLIVEIRA, A.R. Sobre o alcance teórico do conceito "exclusão". Civitas, Porto Alegre, v. 4, n. 1, p. 159-188, jan./jun. 2004 b.

PAUGAM, S. La constitution d'un paradigme. In: Paugam, S. (Org.). L'exclusion: l'état des savoirs. Paris: La Découverte, 1996. p. 7-19.

PIERUCCI, A.F. Ciladas da diferença. São Paulo: Editora 34, 1999.

POCHMANN, M.; AMORIN, R. (Org). Atlas da exclusão social no Brasil. 3. ed. São Paulo: Cortez, 2004.

SANTOS, B.S. Pela mão de Alice: o social e o político na pós-modernidade. 2. ed. São Paulo: Cortez: 1996.

SANTOS, B.S. A crítica da razão indolente: contra o desperdício da experiência. São Paulo: Cortez, 2000. 
Da pedagogia do oprimido às pedagogias da exclusão: um breve balanço crítico

SANTOS, B.S. A gramática do tempo: para uma nova cultura política. São Paulo: Cortez, 2006.

SARTI, C. A familia como espelho: um estudo sobre a moral dos pobres. Campinas: Autores Associados, 1996.

SEMERARO, G. Libertação e hegemonia: chaves de filosofia política na educação brasileira. In: Passos, L.A.; Semeraro, G.; Torres, A. (Org.). Educação, fronteira política. Cuiabá: UFMT, 2006. p. 19-36.

SILVA, M.O.S. A inclusão vs. exclusão social na perspectiva das políticas públicas: o caso brasileiro. Trabalho apresentado na reunião da Latin American Studies Association (LASA), Montreal, 2007.

SPOSATI, A. Exclusão social abaixo da linha do Equador. In: SEMINÁRIO DE EXClUSÃo SOCIAL - PUC/sP, com Sergé Paugam e Lúcio Kowarick, 23 abr. 1998. (digitado).

STOER, S.R.; MAGALHÃES, A.M.; RODRIGUES, D. Os lugares da exclusão social: um dispositivo de diferenciação pedagógica. São Paulo: Cortez, 2004.

STRECK, D.R. Pedagogia no encontro de tempos: ensaios inspirados em Paulo Freire. Petrópolis: Vozes, 2001.

STRECK, D.R. O Fórum Social Mundial e a agenda da educação popular. Revista Brasileira de Educação, Belo Horizonte, n. 26, p. 58-69, maio/ago. 2004.

TORRES, R.M. Los multiples Paulo Freires. Cadernos de Educação, Pelotas, n. 29, p. 31-44, jul.-dez. 2007.

XIBERRAS, M. As teorias da exclusão: para uma construção do imaginário do desvio. Lisboa: Instituto Piaget, 1993. 